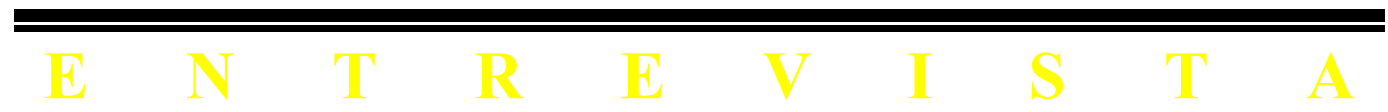




\section{ENTREVISTA A BRUCE ACKERMAN}

Me gustaría conocer qué factores influyeron en su decisión de estudiar derecho, y por qué se interesó por la Teoría Constitucional y la Filosofía Política.

Mis memorias más tempranas, fuera de las familiares, tienen que ver con el derecho, la justicia y la política de los primeros años de la década de los 50: la cruzada anticomunista de McCarthy y los primeros esfuerzos de integración racial por parte del Tribunal Supremo de Estados Unidos. ¿Qué significaba todo ello? Mis años de estudiante en Harvard durante la década de los 60 no me dieron una respuesta a este interrogante. Casi sin excepción, los cursos de filosofía política en los que me concentré estaban orientados históricamente, y no hacían ningún esfuerzo por confrontar las realidades contemporáneas. En retrospectiva, estoy agradecido por la excelente formación académica que recibí. Pero durante aquel tiempo debo confesar que me aburría bastante.

Excepciones. Judith Shklar era brillante. John Rawls acababa de llegar a Cambridge, aunque pude tomar unos cursos con él antes de que dejase Harvard para ir a la Yale Law School en 1964. Yale era un lugar extraordinario. Lleno de gente activa de distintas tendencias, con mentes muy incisivas: Ronald Dworkin, Charles Reich, Guido Calabresi, Alexander Bickel o Robert Bork, por nombrar sólo a unos pocos. El mundo también estaba lleno de movimientos en los que yo de alguna manera participaba (aunque no como líder): los derechos civiles, las protestas anti-Vietnam... Si la vida política en Estados Unidos hubiese evolucionado en la dirección de la socialdemocracia, no sé si yo hubiese optado por la academia. Pero no evolucionó en esa dirección y opté por la academia. 
2. ¿Cómo caracterizaría la atmósfera intelectual hoy en día en las facultades de Derecho de Estados Unidos?

Éste es un gran momento para ser un profesor en Estados Unidos. No ha habido muchos períodos y lugares en la historia donde uno pueda encontrar una discusión jurídica de comparable dinamismo y creatividad.

\section{Recientemente Vd. llegó de Alemania. ¿Qué razones le llevaron alli?}

El derecho americano y la filosofía estadounidense son, por supuesto, increíblemente insulares y auto-satisfactorios. Por ello, a comienzos de los 80 me pregunté: ¿dónde está sucediendo algo interesante en relación con la filosofía?; ¿dónde tenemos una cultura jurídica rica que haya confrontado cuestiones básicas? Pensé que Alemania era mejor que Francia en ambos aspectos. Pero eso era una mala noticia para mí, pues hablaba francés pero no alemán. Lamentablemente, me llevó diez años aprender a escribir y hablar alemán con facilidad. Sólo entonces pude aceptar una oferta para pasar un año en la Wissenschaftskolleg de Berlín.

La Wissenschaftskolleg es realmente una institución hermosa. Sin embargo, me deprimieron bastante las condiciones de trabajo de los profesores alemanes, y de los profesores europeos en general. Francamente, no estaba preparado para una experiencia tan profundamente desmoralizante. Sabía, por supuesto, que los europeos estaban sobrecargados de estudiantes y de obligaciones burocráticas y, además, sabía que les pagaban poco, especialmente fuera de Alemania; pero encontré algo más preocupante. La gente no parece estar preparada para pensar por sí misma, para valerse de lo que tiene. Parecen más cómodos jugando el rol de comentadores, escondiendo sus propias ideas detrás de un gran nombre del pasado, Kelsen o Schmitt (para aquellos que se animan a vivir más cerca del peligro).

Esto es trágico, y aún más cuando es obvio que los académicos debemos teorizar acerca de nuevas realidades. Desde el punto de vista práctico, ahora existe la Comunidad Europea, que ya ha cambiado masivamente las relaciones entre los tribunales y los legislativos. Pero en un nivel más fundamental, el claro fracaso del marxismo en la teoría y en la práctica requiere una sistemática reconceptualización de la teoría jurídica y política, especialmente para todos aquellos que, como yo, seguimos comprometidos con la búsqueda de la justicia social en el Estado liberal frente a la tendencia de los partidarios de Hayek, que quieren convertir el «liberalismo» en una fe oscurantista en la «mano invisible» del mercado. 
4. Viniendo de Alemania, tengo una pregunta que resulta obligada. ¿Cómo ve usted su trabajo en comparación con el de Jürgen Habermas?

Habermas y yo empezamos de tradiciones filosóficas del siglo XIX bien diferentes. Él empezó a partir del marxismo. Yo empecé a partir del liberalismo. Creo que es muy significativo que ambos hayamos usado la misma idea básica, el diálogo, para responder a las dificultades que confrontábamos cuando intentábamos darle sentido actual a nuestras diferentes tradiciones filosóficas. Por supuesto, hay mucho que decir acerca de mi relación con Habermas. Por ejemplo, es sorprendente que Habermas nunca haya intentado escribir los diálogos que podrían suceder en su «situación ideal de diálogo». Esto es precisamente lo que yo intenté hacer en «Social Justice in the Liberal State» ${ }^{1}$. Según yo entiendo a Habermas, nada en su teoría impide que haga este esfuerzo de imaginación política. Pero hasta que lo haga es difícil decir cuáles son nuestros desacuerdos. Puede que algunas de nuestras diferencias se deban meramente a diferencias en nuestros respectivos idiomas filosóficos, mi preferencia anglosajona por la claridad y llaneza y su germánico deseo de erudición y profundidad.

5. Lo que siempre me impresionó es su versatilidad para trabajar en Teoría Constitucional y en Filosofía Política con la misma profundidad. Pero siempre encontré un resquicio de contradicción entre la ontología que usted maneja en su Teoría Constitucional y la que maneja en su Filosofía Política. La primera me parece una ontología de la especie "liberal-individualista» mientras que la segunda parece de la especie «histórica-supraindividual». ¿Cómo explica usted esta impresión?

Me tomó alrededor de 10 años escribir «Social Justice in the Liberal State». Yo tenía 37 años cuando fue publicado y me prometí no pasarme el resto de mi vida defendiendo las ideas del libro. En cambio, traté de trabajar nuevas ideas, sin preocuparme demasiado de la relación que estas nuevas ideas tenían con mis ideas más antiguas. Justo ahora, con la publicación del primer volumen de «We the People» $\mathrm{y}$ «Future of Liberal Revolution» he empezado a confrontar las cuestiones fundamentales que se me presentan al yuxtaponer al joven Bruce con el Bruce de mediana edad.

Quizá la tensión a la que usted se refiere no es tan fundamental como parece a primera vista. Yo, por ejemplo, en lugar de contrastar

${ }^{1}$ Véase la versión castellana de este libro: La justicia social en el Estado liberal, introducción y traducción de Carlos Rosenkrantz, Centro Estudios Constitucionales, Madrid, 1993, 418 págs. 
la ontología liberal-individualista de «Social Justice» con la ontología «histórica-supraindividual» de «We the People», señalaría los temas comunes de ambos trabajos. En este sentido, la necesidad del diálogo requiere una exploración de las formas de cultura política disponibles en occidente, incluyendo la tradición del liberalismo occidental y la tradición del constitucionalismo, que por cierto no son la misma tradición. Sólo si nos situamos en nuestra cambiante cultura podemos empezar a entender qué es lo que realmente somos en tanto seres políticos en una sociedad liberal.

6. En relación con su trabajo filosófico, su idea de la Neutralidad es una representación, una teatralización diría yo, de la idea de que el liberalismo no está basado en juicios controvertibles acerca del valor intrínseco de diferentes formas de vida. De todos modos, si lo entiendo correctamente, usted no niega que el liberalismo implica valores acerca de la mejor sociedad y la mejor forma de organizar el conflicto social. ¿Piensa usted que estos valores pueden defenderse desde un punto de vista Neutral? En otras palabras, ¿existe una defensa Neutral del valor de la autonomía?

El diálogo político es Neutral desde el momento en que sus participantes se oponen a justificar el uso del poder coercitivo sobre la base de que ellos tienen una especial información acerca de los misterios morales del universo. Dada esta visión, es un error categorial pensar que puede existir una defensa Neutral del Diálogo Neutral. Por el contrario, el Diálogo Neutral es él mismo un valor fundamental.

Existen muchas formas diferentes de defender este valor. Algunas son neo-kantianas, basadas en la idea de autonomía. Algunas son religiosas, basadas en el sacrilegio en el que incurren los políticos, o cualquier persona, que sostiene que tiene una visión superior acerca de la naturaleza de la vida buena o valiosa. Algunas son pragmáticas, basadas en la corrupción del poder y la facilidad con que las afirmaciones de una superior visión acerca de la naturaleza de la vida buena o valiosa pueden justificar la perpetración de inefables formas de opresión. Estas son razones muy fuertes en apoyo del Diálogo Neutral; creo que es una trivialización llamarlas «preferencias».

Aunque todas estas razones son muy significativas para mí, yo pongo otras consideraciones en el centro de toda mi obra: el esfuerzo humano de encontrar su lugar mediante la conversación interpersonal con otros y el imperativo de diseñar una clase de conversación que no sofoque el espacio vital de la cultura de cada individuo, es decir, sus propios esfuerzos para crear una forma de pensamiento y de práctica que a él, o ella, le desvelen los misterios del universo. 
Este último párrafo, ¿sugiere un «ideal sustancial del bien»? Ésta es una frase que ha tomado muchos sentidos técnico-filosóficos distintos, y deberíamos conversar durante mucho tiempo para encontrar cuál de estas formas técnicas representa algo importante.

9. Con respecto a su teoría constitucional, ¿considera que su teoría es una teoría normativa acerca de la forma en que una «polis» moderna debe organizarse o es sólo un ejercicio de autoentendimiento?

En el centro de mi teoría constitucional de la democracia dualista existe la siguiente pregunta: ¿Qué es realista esperar de ciudadanos comunes que viven en una sociedad moderna y diferenciadora caracterizada por la división del trabajo? Obviamente, es totalmente irrealista esperar la clase de compromiso cívico que esperaba encontrar Rousseau. Pero, ¿quiere decir ello que debemos preparamos para el «corsé de hierro» de la burocracia envuelta en el formalismo del voto?

No creo que ésta sea una pregunta únicamente para los estadounidenses, por lo que creo que mi teoría constitucional debe tener un atractivo más amplio, aunque reconozco que existen peculiaridades en la versión estadounidense de la democracia dualista que no garantizan la emulación.

10. Su teoría constitucional no dice mucho acerca de la ingeniería constitucional, esto es, acerca de la forma institucional de garantizar los resultados recomendados por la teoría. Me gustaría que usted hablase un poco sobre lo que debería hacerse en una convención constituyente de un país que, como los de Latinoamérica o los del Este europeo, ha decidido romper con el pasado. ¿Cuáles son las normas que deben incorporarse a esa constitución, qué es lo que debe dejarse para lo que usted denomina «la política en los tiempos normales o corrientes»?

Mi reciente libro «The Future of Liberal Revolution»sugiere la posible relevancia de mi teoría para la presente situación en Europa. El artículo que escribimos juntos y que publicamos en la Revista del Centro de Estudios Constitucionales, empieza a explorar la relación de la teoría dualista en la Argentina. Pero, obviamente, existe mucho más trabajo por hacer.

11. Me parece que alguien podría pensar que desde su perspectiva no debería dudarse de la legitimidad del gobierno de Fujimori en el Perú, sobre la base de que ha sido apoyado por la mayoría de 
la gente en un «momento constitucional», esto aun cuando Fujimori disolvió un congreso elegido popularmente. Pero existe un sentimiento de que lo que Fujimori hizo está mal o es incorrecto. ¿Es este sentimiento una prueba de que su teoría está equivocada, es que bajo la debida reflexión debemos abandonar este sentimiento o, finalmente, es que hay una mala interpretación de su teoría?

Mi teoría no apoya los «golpes» del tipo del de Fujimori. Ello es así, pues antes de que el Pueblo pueda hablar con la voz de los «momentos constitucionales», debe existir un movimiento político que durante muchos años construya el apoyo y movilice el consentimiento de crecientes proporciones de la población, hasta el punto de que pueda decirse creíblemente que habla la voz del juicio de la mayoría de la población.

12. Por último, ¿me podría decir algo acerca de los proyectos en los que está trabajando en el presente y qué es lo que usted espera de ellos?

En este preciso momento, estoy terminando el segundo volumen de «We the People». En un año o dos, espero estar en condiciones de empezar algunos proyectos genuinamente nuevos. 